\title{
A COMPARITIVE STUDY ON INDUCTION OF LABOUR VERSUS EXPECTANT MANAGEMENT IN TERM PREMATURE RUPTURE OF MEMBRANES IN TERTIARY CARE HOSPITAL ,VISAKHAPATNAM .
}

\section{Dr Kavitha Gayak}

\section{Dr Nirupama Palakodeti*}

\section{Ms Obg ,associate Professor , Department Of Obstetrics And Gynaecology, Gitam Institute Of Medical Sciences And Research , Rushikonda, Visakhapatnam, ap.}

Ms Obg , Assistant Professor, Department Of Obstetrics And Gynaecology, Gitam Institute Of Medical Sciences And Research, Rushikonda, Visakhapatnam,ap. * Corresponding Author

\section{ABSTRACT Premature rupture of membranes (PROM), also called Prelabour Rupture Of Membranes, is classically} defined as rupture of membranes before labour and accounts for $0.8-0.9 \%$ of all pregnancies at term. this study was conducted over a period of 14 months ( from March 2018 to May 2019) in a tertiary care medical college. A total of 100 term PROM patients were recruited in our study - and divided into two groups randomly--50 (Group $\bar{A}$ ) patients were managed conservatively and 50 (Group-B) patients underwent induction of labour. Both these patient groups were studied to compare the feto-maternal outcome. Group-A (conservative management group) patients were observed to await the spontaneous onset of labour pains for at least 24 hours. Patients in group B were induced with either - PGEl tab (misoprostol) $25 \mu$ gm 4 hourly orally or iv oxytocin infusion. the PROM-delivery interval was < 12 hours in $72 \%$ of induced groups (Group B) and $10 \%(5)$ in group- $A$ (conservative or expectant group). LSCS rate was $10 \%$ in group-A (expectant group) \& $15 \%$ in group -B (induced group). Sepsis rate, maternal and fetal, hospital stay, NICU admission \& duration of NICU stay were notably higher in group - A (expectant management group). therefore, from our study we concluded that immediate induction of labour in term PROM cases shortens the PROM- delivery interval, hospital stay, NICU stay and reduction in both maternal \& neonatal sepsis.

\section{KEYWORDS : Term PROM, induction of labour, feto-maternal outcome, neonatal sepsis, NICU, expectant} management

\section{INTRODUCTION:}

Premature or Prelabour Rupture Of Membranes is classically defined as the rupture of integrity of the fetal membranes before the onset of labour and resulting in leakage of amniotic fluid. $(2,3,4$,$) .Pre-labour rupture of membranes without$ spontaneous uterine contractions complicate approximately $10 \%$ of all pregnancies, out of which $80 \%$ occurs at term (5).the management of PROM at term remains a matter of great debate till date. While induction of labour has resulted in decreased incidence of maternal \& fetal sepsis, but it is also associated with a higher incidence of caesarean section rate due to fetal distress and uterine hyperstimulation. Kappy et al in their study, reported a higher incidence of operative deliveries in term pregnancies with ruptured membranes managed with labour stimulations compared with those who were managed expectantly.(6). Approximately $65-75 \%$ of term PROM patients are followed by spontaneous onset of labour within 24 hours (7). Prostaglandins- PGE2\& PGEl have been used for cervical ripening and myometrial stimulation in unfavorable cervices with low Bishop's pre- induction score. It is seen that in patients who had expectant management, with prolonged hospitalization without active intervention with uncertain fetal and neonatal prognosis, many a times leads to maternal psychological sequelae.(8)

\section{MATERIALS \& METHODS:}

Study type: Hospital based prospective observational study. Study duration: Fourteen months

Study period: March 2018 to April 2019

Study subjects: Women with term PROM as per inclusion \& exclusion criteria

Study place - department of obstetrics and gynaecology , githam institute of medical sciences and research rushikonda, visakapatnam, AP, India.

\section{INCLUSION CRITERIA:-}

1. Gestational age 37-40 weeks

2. Singleton pregnancy
3. Age $20-30$ years

4. Adequate pelvis

5. Vertex presentation

\section{EXCLUSION CRITERIA:-}

1. Age $<20$ years, $>30$ years

2. Gestational age $<37$ weeks, $>40$ weeks

3. Multiple pregnancy

4. Chorioamnionitis

5. Medical disorders

6. Obstetric complications

7. Grand multipara

8. Previous LSCS

9. Meconium stained liquour

1. Cephalopelvic disproportion

2. Malpresentation

3. Intrauterine fetal death

All the patients who fulfilled the inclusion and exclusion criteria were subjected to a detailed history taking followed by thorough clinical examination including general and systemic examination to rule out any exclusion criteria. A thorough obstetrical examination including per speculum examination and Bishop's scoring was conducted. An obstetric ultrasonography and CTG were performed. All the patients were given IV antibiotics of 1 gram ceftriaxone, $100 \mathrm{ml}$ metronedazole and gentamycin $80 \mathrm{mg}$ after negative skin test till delivery. Informed written consent was taken and patients were randomly allocated to either Group A (expectant or conservative management group) or Group B (active management group with induction of labour). Patients in Group-B (active management group) were induced according to Bishop's pre- induction score. PGE 1 tablet (misoprostol) $25 \mu \mathrm{m}$ orally was given if Bishop's score was less than 5 followed by repeat dose after 4 hours or iv oxytocin at the rate of 5 units in $500 \mathrm{ml}$ RL or Normal Saline ( for primigravida) or @ 1- 2 units for multigravida) and the drip was titrated in escalating doses till optimal response was observed as evidenced by onset of effective uterine contractions. All these patients had vitals charting, pulse, temperature, blood

Submitted : $27^{\text {th }}$ July,2019

Accepted : $15^{\text {th }}$ August,2019

Publication : $15^{\text {th }}$ October, 2019

GJRA - GLOBAL JOURNAL FOR RESEARCH ANALYSIS 27 
pressure along with progress of labour- fetal heart rate, uterine contractions and decent of head. Patients in Group-A (expectant management group) were kept for observation with sterile vulval pad for 24 hours to await spontaneous onset of labour pains. Vitals charting (pulse rate, temperature, blood pressure), uterine contractions fetal heart rate, colour of liquour were monitored carefully. Unnecessary vaginal examinations were avoided and $\mathrm{P} / \mathrm{V}$ exam done only if the uterine contractions were good, to gauge the progress of labour. In this group, most of the patients went into spontaneous labor in 24 hours. Induction of labour was done after 24 hours if there were no contraction. Emergency LSCS was done for indications like fetal distress, non progression of labour, cord prolapse, failed induction, and chorioamnionitis. All labour and delivery events were noted example vaginal delivery, spontaneous or instrumental-forceps/ventouse, LSCS etc. e fetal outcomes were noted namely APGAR score, birth weight, neonatal sepsis, NICU admissions and care required. All the patients were followed up in puerperium to assess maternal pyrexia, sepsis and neonatal sepsis.

\section{RESULTS :}

the results and observations of the present study are as follows : Most of the patients were primigravidae, had low education levels, hailed from rural background and from low socio-economic stratum, young aged and mostly unbooked.

Table 1 : Distribution of patients according to parity

\begin{tabular}{|l|c|c|c|c|}
\hline & \multicolumn{2}{|c|}{$\begin{array}{c}\text { Group -A (Expectant } \\
\text { Management) }\end{array}$} & \multicolumn{2}{c|}{ Group- B(Induced) } \\
\hline Primigravida & 27 & 54.0 & 22 & 44.0 \\
\hline Multigravida & 23 & 46.0 & 28 & 56.0 \\
\hline Total & 50 & 100.0 & 50 & 100.0 \\
\hline
\end{tabular}

Table 2 : Mode of delivery

\begin{tabular}{|l|c|c|c|c|}
\hline \multirow{2}{*}{} & \multicolumn{2}{|c|}{$\begin{array}{c}\text { Group - A } \\
\text { (Expectant) }\end{array}$} & \multicolumn{2}{c|}{$\begin{array}{c}\text { Group-B } \\
\text { (Induced) }\end{array}$} \\
\cline { 2 - 5 } & Number & $\%$ & Number & $\%$ \\
\hline Vaginal delivery & 45 & 90.0 & 41 & 82.0 \\
\hline Spontan eous delivery & 38 & 56.0 & 28 & 56.0 \\
\hline Ventouse delivery & 05 & 10.0 & 8 & 16.0 \\
\hline Forceps delivery & 02 & 4.0 & 5 & 10.0 \\
\hline LSCS & 5 & 10.0 & 9 & 18.0 \\
\hline Total & 50 & 100.0 & 50 & 100.0 \\
\hline
\end{tabular}

Table 3: PROM- delivery interal (PDI)

\begin{tabular}{|l|l|l|l|l|}
\hline & \multicolumn{2}{|l|}{ Group-A (Induced) } & \multicolumn{2}{l|}{ Group-B (Induced) } \\
\hline Time & Number & $\%$ & Number & $\%$ \\
\hline$<12$ hours & 5 & 10.0 & 36 & 72.0 \\
\hline $12-24$ hours & 35 & 70.0 & 11 & 22.0 \\
\hline$>24$ hours & 10 & 20.0 & 3 & 6.0 \\
\hline Total & 50 & 100.0 & 50 & 100.0 \\
\hline
\end{tabular}

Table 4 : Maternal outcome

\begin{tabular}{|l|c|c|c|c|}
\hline \multirow{2}{*}{} & \multicolumn{2}{|c|}{ Group- A (Expectant) } & \multicolumn{2}{c|}{ Group-B (Induced) } \\
\cline { 2 - 5 } & Number & $\%$ & Number & $\%$ \\
\hline Fever & 3 & 6.0 & 1 & 2.0 \\
\hline PPH & 5 & 10.0 & 6 & 12.0 \\
\hline Sepsis & 5 & 10.0 & 3 & 6.0 \\
\hline Nil & 37 & 74.0 & 40 & 80.0 \\
\hline Total & 50 & 100.0 & 50 & 100.0 \\
\hline
\end{tabular}

Table 5 : Neonatal outcome

\begin{tabular}{|l|c|c|c|c|}
\hline \multirow{2}{*}{} & \multicolumn{2}{|c|}{ Group- A(Expectant) } & \multicolumn{2}{c|}{ Group-B(Induced) } \\
\cline { 2 - 5 } & Number & $\%$ & Number & $\%$ \\
\hline Birth asphyxia & 14 & 28.0 & 8 & 16.0 \\
\hline Mild APGAR $<7$ & 10 & 20.0 & 6 & 12.0 \\
\hline Severe APGAR $<5$ & 4 & 8.0 & 2 & 4.0 \\
\hline Sepsis & 2 & 4.0 & 0 & 0.0 \\
\hline $\begin{array}{l}\text { Stillbirth } \\
\text { /early neonatal }\end{array}$ & 0 & 0.0 & 0 & 0.0 \\
\hline
\end{tabular}

\begin{tabular}{|l|c|c|c|c|}
\hline Nil & 36 & 72.0 & 42 & 84.0 \\
\hline Total & 50 & 100.0 & 50 & 100.0 \\
\hline
\end{tabular}

\section{DISCUSSION}

In our study, the women in both the Group A (expectant management group) and Group-B (Induced group) were comparable with respect to mean maternal age, gestational age , parity, educational status, socio-economic background, urban-rural distribution. Since their socio-demographic profile was similar, therefore, any difference in outcome in these two groups was primarily due to different management protocols and not due to demographic differences.In our study we observed that vaginal delivery occurred in $90 \%$ of Group $A$ and $82.0 \%$ in Group-B (Induced) patients. A study by Shanti K et al stated LSCS rate as $5.7 \%$ in the expected group as compared to $12 \%$ in active group (9). In another study by Suneela $\mathrm{K}$ at al, there were $88.3 \%$ vaginal delivery in expectant group and $85.0 \%$ in active management group i.e , $11.7 \%$ LSCS rate in expectant group and $15 \%$ in induced group.(1)In our study, we observed intrapartum pyrexia in 65 of expectant group (Group-A) versus $2 \%$ in Group-B (Induced group). Suneela $\mathrm{K}$ et al reported $3.3 \%$ pyrexia in induced group and $5 \%$ in expectant group (1). Sumaira Yasmeen et al (Peshawar) reported $2.4 \%$ in induced group \& $16 \%$ fever in expectant group (10). In our study, PPH occurred in $10 \%$ Group-A \& 12\% Group-B, whereas Suneela K et al reported $6.7 \% \mathrm{PPH}$ in expectant group \& $10 \%$ in induced group(1).this result may be because of the fact that-induction of labour has a higher incidence of $\mathrm{PPH}^{\prime \prime}$. $(1,2)$.In our study, $28.0 \%$ babies in Group-A suffered from birth asphyxia (severe-8\% and mild$20 \%$ ) as compared to $16.0 \%$ in Group- B (mild- $12 \%$ \& severe 4\%).Neonatal sepsis was observed in $4 \%$ of Group A and in none (0\%) in Group B .this may be attributed to the fact that there was a prolonged - delivery interval in Group A (expectant group).there were no stillbirths or early neonatal deaths in either groups. In her study, Suneela K et al reported severe birth asphyxia requiring ventilation in $6.6 \%$ in the expectant group and neonatal sepsis was reported as $11.7 \%$ in the expectant group.(1) Active management in cases of PROM at term has shown many benefits in terms of reducing the latent period and better maternal satisfaction (8).Induction of labour in such cases not only reduces the PROM -delivery interval but also reduces neonatal and maternal sepsis without much significant rise in LSCS rate. It is clear that nearly $70 \%$ of term PROM patients go into spontaneous labour without induction within 24 hours. e method of induction whether PGEl (misoprostol) or oxytocin depends on Bishop's pre-induction score or cervical findings.

\section{CONCLUSION -}

In our study we concluded that with induction of labour in patients with PROM at term, the PROM delivery interval was reduced along with significantly better maternal satisfaction and feto maternal outcome. the expectant group who underwent conservative management had higher maternal and fetal morbidity, sepsis, longer hospital and NICU stay causing anxiety and distress to both patients and clinicians.Therefore, in all patients presenting with premature rupture of membranes at term should be actively managed with induction of labour after assessing the cervical condition according to the Bishop's pre-Induction score so as to reduce the incidence of maternal and fetal sepsis and morbidity.

\section{REFERENCES}

1. Suneela Ket al,Sch.J.App.Med.Sci, April 2016, 4 (40): 1424- 1427

2. Gary Cunningham F et al ; Normal Labour Chapter 22, William Obst-24thEd NY, Mc Gram Hill -2014; $886-933 ; 948$.

3. Larranga - Azcarate $\mathrm{C}$ at al ; Dinoprostone Vaginal slow release system compared to expectant management in the active treatment of PROM at term impact on maternal and fetal outcome ; Actaobstetria , $2008 ; 87$ (2) : 195-200.

4. Shah K et al- PROM at term: early induction versus expectant management; e J. ob. Gynec. India 2012; 62 (2): 172-175.

5. Duff P: PROM in term patients: Induction of labour versus expectant management; clinObstetGynecoll998:41:883-891.

6. Kappa KA et al;PROM: conservative approach Am. J. obs. Gyn 1979;134: 655. 
7. Hoffmann RA et al: Oral misoprostol versus placebo in the management of PROM at term; Int. J of GynecObstet. 2001;72: 215-221.

8. Term Prelabour rupture of membranes: e Royal Australian \& NZ College of Obs\&Gyn(C-obs 36) 1-9.

9. Shanti $\mathrm{K}$ et al: Comparative study of active vs expectant management and maternal and neonatal outcome in PROM: IOSR JDMSS; 2015; 14(4):34-9.

10. Sumaira Yasmeen et al: Active versus conservative management of PROM at term. J Postgrad Med Inst 2013; 27(1): 63-68. 